Journal of Innate

Immunity
J Innate Immun 2013;5:100-113

DOI: $10.1159 / 000345700$
Received: August 17, 2012

Accepted after revision: November 8, 2012

Published online: January 15, 2013

\title{
Serum Acute Phase Protein and Inflammatory Cytokine Network Correlations: Comparison of a Pre-Rheumatoid Arthritis and Non-Rheumatoid Arthritis Community Cohort
}

\author{
Alfonse T. Masi Azeem A. Rehman Kevin B. Elmore Jean C. Aldag \\ University of Illinois College of Medicine, Peoria, III., USA
}

\section{Key Words}

Acute phase proteins - Inflammatory cytokines - Cytokine receptors $\cdot \mathrm{IL}-1 \mathrm{ra} \cdot \mathrm{Rheumatoid}$ arthritis $\cdot$ Case-control study · Pre-RA · ELISA assays · Principal component analysis

\begin{abstract}
Serum concentrations of acute phase proteins, inflammatory cytokines, and other immunological components were individually assayed using high-sensitivity ELISA in a community-based cohort of preclinical rheumatoid arthritis (pre-RA) and matched non-RA control (CN) subjects. Bivariate correlations of the biomarker panel concentrations were compared in pre-RA versus $C N$ and female versus male subjects. Clinically elevated CRP levels $(8+\mathrm{mg} / \mathrm{l})$ occurred in a higher $(p=0.010)$ frequency in 46 pre-RA $(n=8,17.4 \%)$ subjects than in $179 \mathrm{CN}(n=9,5.0 \%)$, and were independent of age, gender, smoking behaviors, and serum rheumatoid factor. Selected age and gender differences were found in levels of the immunological network factors. In each study group, the ratio of sTNF-RI to IL-2sR $\alpha$ mean concentrations was 2-fold higher in men than in women. Aging correlated positively with CRP, ASAA, and TNF- $\alpha$ levels, but negatively with IL-1 $\beta$. Bivariate correlations were similar in pre-RA subjects versus $\mathrm{CN}$ and by gender, with few exceptions. Factor loadings in principal component analysis of the total sub-
\end{abstract}

jects indicated that age- and gender-related variables constituted the two main components. Using multiple regression analyses, an integrative working model of all variable interrelations was generated. The tentative, directional model supports a concept of gender dimorphism of the ratio of sTNF-RI to IL-2sR $\alpha$ serum concentrations and displays differing effects of age on TNF- $\alpha$ versus IL-1 $\beta$ levels. These findings indicate complex age, gender, and cytokine interrelations in control of the immune systems network. Future research in testing such inflammatory pathways promises a better understanding of predisposition to diseases, like RA.

Copyright $\odot 2013$ S. Karger AG, Basel

\section{Introduction}

Serum acute phase proteins (APPs), inflammatory cytokines, their receptors, and antagonists are integrated components of the immunological network, which is under complex systems biological control during health and varied clinical diseases [1-4]. Animal and basic investigations support the concept that interactions of multifunctional pro-inflammatory cytokines and APPs regulate immune responses and inflammatory reactions [5-8]. However, few reports in humans quantify either concurrent serological concentrations of inflammatory immu-

\section{KARGER \\ Fax +41613061234 \\ E-Mail karger@karger.ch}

www.karger.com
(C) 2013 S. Karger AG, Basel

$1662-811 \mathrm{X} / 13 / 0052-0100 \$ 38.00 / 0$

Accessible online at:

www.karger.com/jin
Prof. Alfonse T. Masi

University of Illinois College of Medicine

One Illini Drive

Peoria, IL 61656 (USA)

E-Mail amasi@uic.edu 
nological profiles or their correlational patterns in normal populations $[2,9,10]$ or in susceptible persons prior to the clinical onset of chronic disease, like rheumatoid arthritis (RA) [11-13].

Serum levels of APPs, like C-reactive protein (CRP) and acute-phase serum amyloid-A (ASAA), are robustly increased above normal concentrations in acute infectious diseases and are strongly correlated [14]. Levels of these APPs may also be elevated in chronic inflammatory diseases, like RA $[1,5,15]$ and may be strongly correlated $[16,17]$. The inflammatory cytokines, TNF- $\alpha$ and IL-6, also increase during chronic inflammatory disease, like RA $[5,15,16]$. Additionally, serum IL- 6 and CRP levels can increase during physiological aging $[9,10]$. However, little is known about correlations of the other inflammatory immunological network components, especially among community populations.

In a population study design analogous to our own, plasma levels of cytokines and soluble cytokine receptors were quantified in blood donors before the diagnosis of RA and in age-matched healthy controls [12]. Multiple serum immune factors were also recently assayed in patients with RA, their first-degree relatives, and population control subjects [13]. Both of the latter reports [12, 13] utilized a multiplex laser bead technique [18] to quantify the panels of APPs and inflammatory cytokines, rather than the ELISA method for individual factor measurements [19-21], as used in this study.

This case-control study nested in a large, community prospective cohort measured individual concentrations of a panel of serum immunological components using a high-sensitivity ELISA technique in preclinical RA (pre$\mathrm{RA}$ ) and matched non-RA control (CN) study subjects. Concentrations of the immune network factors and their correlational patterns were compared in study groups and between men and women. The aim was to identify possible underlying alterations in immunological patterns long before the clinical onset of RA, and other possible host factors which might affect immune network systems control.

\section{Materials and Methods}

The RA Precursors Study Database at This Institution

Baseline personal data and serum samples from the pre-RA cases and matched $\mathrm{CN}$ subjects in this report were donated to this institution by Operation CLUE I, a pre-existing community-wide prospective study (fig. 1) [22-25]. In 1974, the CLUE I base cohort had enrolled 21,061 residents (12,381 females and 8,680 males) of Washington County, Md., USA. The RA Precursors Study (RAPS) was initiated at this institution in late 1991, after funding was secured to begin multiple immune bioassays on the first set of donated baseline female sera (fig. 1). The total RAPS database includes 270 study subjects, 54 Caucasian pre-symptomatic RA (pre-RA) cases (36 females and 18 males), and 216 cohort CN subjects (144 females and 72 males), matched in a ratio of $4 \mathrm{CN}: 1$ preRA (fig. 1). This research is approved by the UICOMP Institutional Review Board.

This study used the European League Against Rheumatism (EULAR) recommendations for designation of pre-RA cases [26]. All pre-RA cases were diagnosed and confirmed in the practice of the sole rheumatologist in the cohort community, using the American College of Rheumatology (ACR) revised classification criteria [27]. The cases had clinical onsets of RA, 3-20 years (1977-1994), following their 1974 cohort entry, with a median interval of 12.0 years. None of the matched comparison subjects had a diagnosis of RA in the practice of the community rheumatologist. The non-RA subjects $(\mathrm{CN})$ were matched to the pre-RA cases on race and usually within 1 year of age at entry and closest in chronological sequence of enrollment in the cohort, analogous to a preceding case-control study [12]. Non-Caucasians are not included in this RAPS study, as too few enrolled in the CLUE I cohort to permit reliable sampling.

The study design intentionally matched the $\mathrm{CN}$ to pre-RA subjects (4:1 ratio) on age and gender to permit a more specific search for additional determinants of RA other than those already known demographic risk factors $[28,29]$. Potential case and control subjects who had known cancer diagnoses during follow-up were excluded from the RAPS database. Those sera were reserved to study cancer biomarkers, which is the primary purpose of Operation CLUE [22-24].

Several Reference Laboratories Performed Immune Assays from 1992 to 1996

The years when immune tests were performed in the respective referral laboratories as well as the mean concentrations of original reported assays, and other relevant statistical values, are indicated in table 1 and figure 1 . The baseline stored $\left(-70^{\circ} \mathrm{C}\right)$ cohort sera were always analyzed in matched sets of 1 pre-RA and $4 \mathrm{CN}$, without knowledge of subject status. As funding was secured during the interval of 1992-1996, the study subject sera were periodically donated for assays of APPs and cytokines in the referral laboratories.

The first set of sera from 14 baseline pre-RA and $56 \mathrm{CN}$ female subjects was sent frozen by CLUE in 1992 to the Chemistry Research Laboratory at Northwestern University (NWU) for hormonal assays (fig. 1) [25]. Residual sera from the hormonal assays were used to perform the initial CRP tests. An enzyme-linked immunoflow assay (ELIFA) was performed, with a minimum detection limit of $1 \mathrm{mg} / \mathrm{l}$, in the Department of Cell, Molecular, and Structural Biology at NWU [30]. The second set of female cohort sera was derived from 21 pre-RA and $84 \mathrm{CN}$ subjects, who constituted the remaining women eligible for inclusion in study and who had available stored $\left(-70^{\circ} \mathrm{C}\right)$ sera in CLUE I (fig. 1).

In April 1995, sera on the first and second sets of female study subjects were sent frozen from CLUE to Specialty Laboratories, Inc. (SLI), Santa Monica, Calif., USA, for cytokine assays (table 1; fig. 1). The SLI referral laboratory performed duplicate serum assays on: IL-1 $\beta$, IL- 6 (females only), TNF- $\alpha$, soluble TNF receptor I (sTNF RI), IL-1 receptor antagonist (IL-1ra), and IL-2 soluble receptor alpha (IL-2sR $\alpha)$. ELISA Quantikine kits specific for hu- 


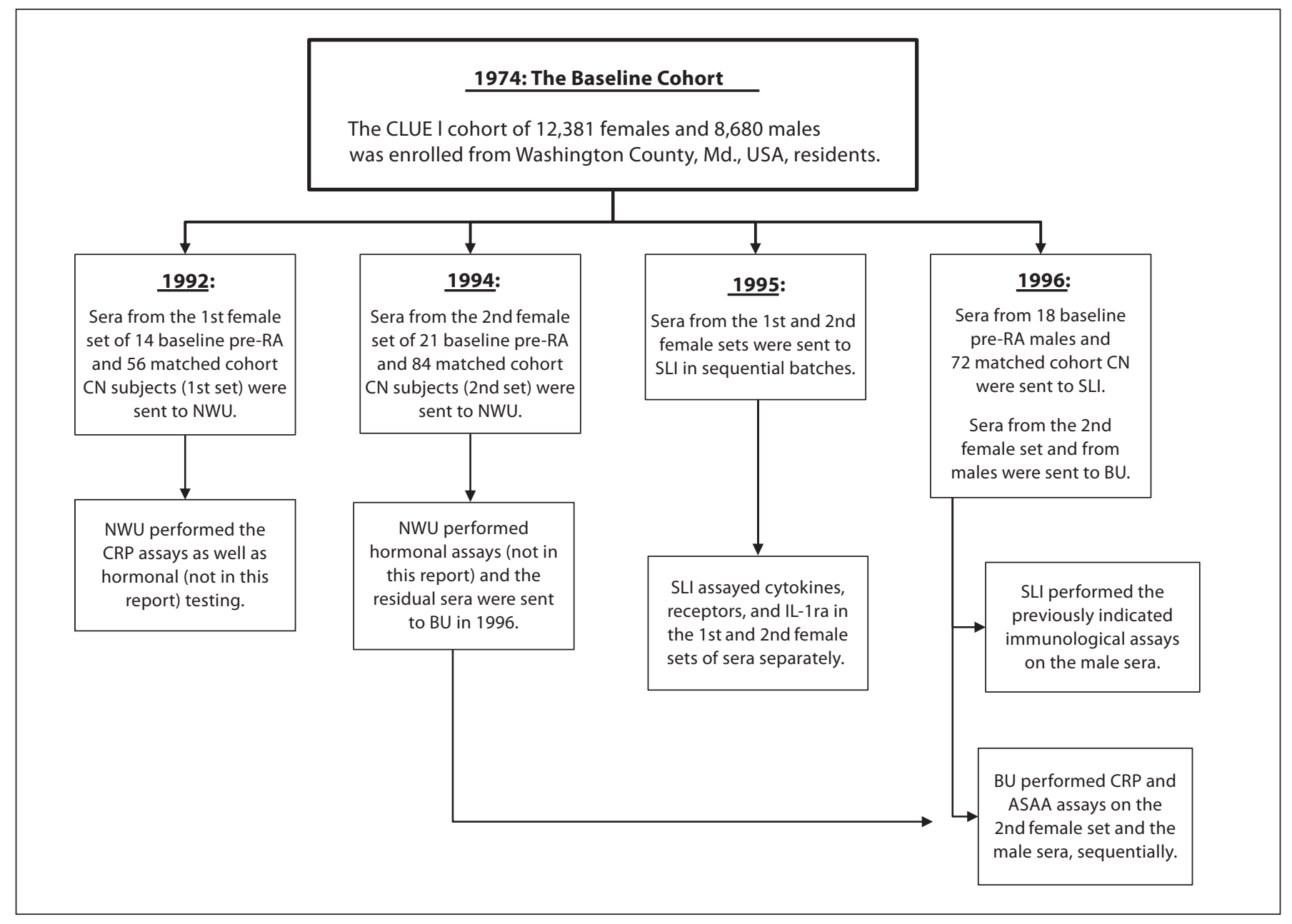

Fig. 1. Outline of subject enrollment in the 1974 CLUE I cohort and the sequential distributions of their baseline sera to referral laboratories for immunoassays in the female and male study groups.

man immunoassays (R\&D Systems, Inc., Minneapolis, Minn., USA) were employed, including high-sensitivity kits for the IL-1 $\beta$, TNF- $\alpha$, and IL- 6 cytokine assays. The first and second set cytokine assays were performed at SLI in sequential runs (table 1; fig. 1) and were analyzed separately.

In April 1996, CLUE approved further serum donations of male pre-RA and CN subjects (fig. 1). Their sera were sent directly to SLI $(1.0 \mathrm{ml})$ for cytokine assays as well as to Boston University (BU) $(0.3 \mathrm{ml})$ for CRP and ASAA assays. BU also performed APP assays on the second set female subjects, using residual sera from NWU, following their completion of hormonal testing (fig. 1). In April 1996, CRP and ASAA assays were performed at $\mathrm{BU}$ on the second set females as well as on all male subjects sequentially (table 1; fig. 1). The first set of female subjects did not have ASAA assays, due to exhausted sera, although they had already had CRP assays performed at NWU, in 1992 (fig. 1). Highsensitivity ELISA (Hemagen, Columbia, Md., USA) methods were used for all APP assays on males and females at BU, with detection limits of $0.1 \mathrm{mg} / \mathrm{l}$ for CRP and $1 \mathrm{mg} / \mathrm{l}$ for ASAA.
Reported Immunoassays on First Set Females Were Normalized to Second Set Female Values

In analyses of combined female assays, the reported first set values were normalized to the second set results, by the respective differences in their means (table 1), after stratification on pre- and post-menopausal cohort entry status. Although all female cytokine assays were performed at SLI in April 1995, results on first and second set women were determined in separate runs. Thus, both the first set CRP (NWU) and the cytokine results (SLI) were adjusted to the second set female values for combined analyses (table 2).

\section{Statistical Methods}

Frequency distributions of variables were examined for acceptability of unimodality and symmetry features. Extreme outliers were observed in several variables, particularly the APPs, as expected for these sensitive and highly reactive tests [17]. Extreme outliers were assigned to the upper ranges observed in the population frequency distribution curves, thereby diminishing their statistical influence [31]. Natural log transformation was performed 
Table 1. Referral laboratories and years when acute APPs and cytokines were assayed

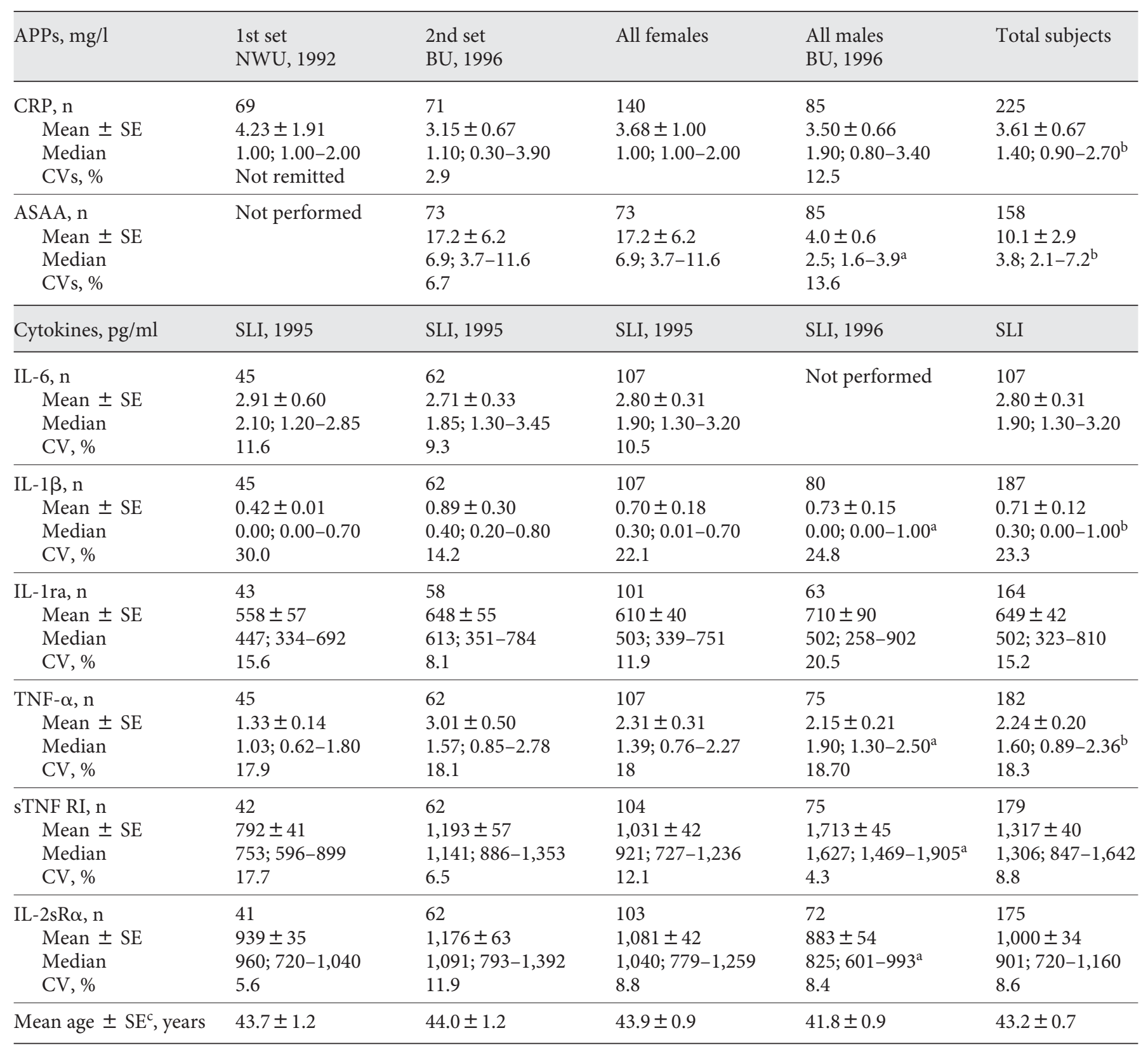

Medians are presented with interquartile range (IQR).

a Spearman's correlations between sexes, adjusted for age $(\mathrm{p}<0.050)$.

b Spearman correlations with age $(\mathrm{p}<0.050)$, see text for details.

${ }^{c}$ ANOVA of subgroup ages $(\mathrm{p}=0.078)$.

on all continuous variables to improve their symmetry in graphics, $t$ tests, principal component analyses (PCAs), and multiple regression analyses (MRAs). Differences in normalized mean values between pre-RA and CN were evaluated using a t test, in female, male, and total subjects, and was further evaluated using the MRA technique. $\mathrm{p} \leq 0.050$ was considered statistically significant in this exploratory study.

Serum Inflammatory Cytokine Network Correlations
Age-adjusted Spearman's rank-order correlation coefficients were used to compare bivariate associations of the immunological variables in gender-specific pre-RA versus $\mathrm{CN}$ subjects. Both age and gender adjustment was performed in comparing immune network factor correlations in total pre-RA versus $\mathrm{CN}$ subjects (see below). The significance of differences between two correlation coefficients of pre-RA versus $\mathrm{CN}$ and male versus female 
Table 2. APP and cytokine assay results in female, male, and combined control versus pre-RA subjects

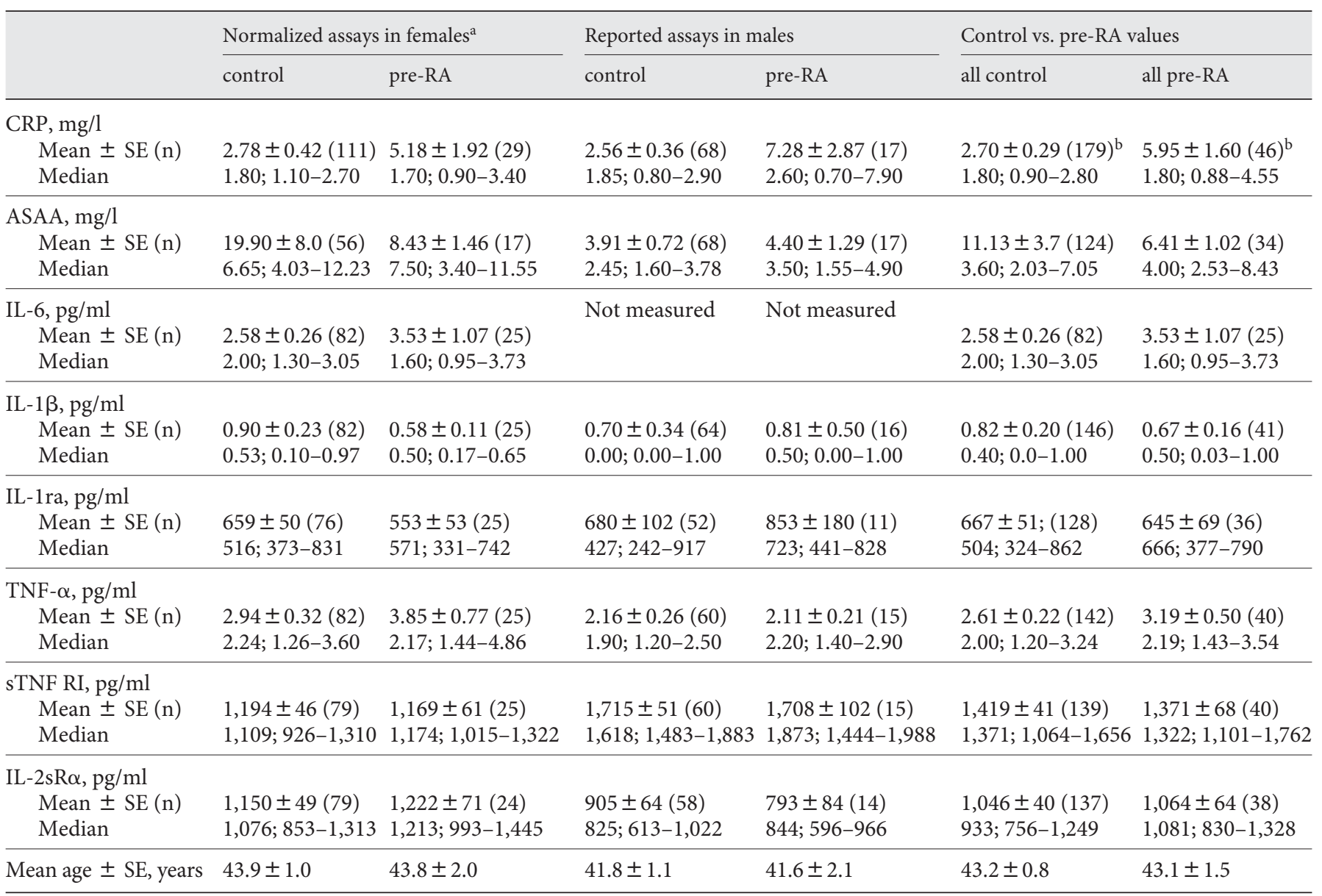

Medians are presented with IQR.

a 1 st set values are normalized to the 2 nd set values within each test for later correlational analyses of the combined control and pre-RA female results.

${ }^{b} \mathrm{p}=0.051$ ( $\mathrm{t}$ test of log-transformed normalized variables, with unequal variances assumed).

groups was estimated using the Fisher r-to-z transformation. PCA, as previously described [25], was performed on log-transformed, normalized immune network values. The IL- 6 cytokine data were not included in PCA, as it was assayed only in females. Also, ASAA data were not included in PCA, since it was only assayed in the second set females. Entry age, gender, and the pre-RA versus $\mathrm{CN}$ variable were included in the PCA models, in addition to the 6 immune network factors.

A working tentative model of directional interrelations of age, gender, and the immune factors was generated using assumptions from PCA and sequential MRA among the total subjects. The integrative model was generated on combined pre-RA and CN subjects for the advantage of a larger sample, and since few differences in concentrations, correlations, or PCA results was observed between study groups (tables 1-7). In PCA, specifically, the study group variable did not bias the regression factor scores of the other derived components, and it did not change the rankings of the other variable loadings. Hence, total data, including pre-RA and $\mathrm{CN}$ subjects, were used to derive the composite variable interrelations among all subjects, using the MRA technique.

\section{Results}

\section{Significant Gender and Entry Age Effects on Immune}

Network Factors

The reported assay results are summarized by gender and by the first and second sets of female cohort study subjects (table 1). In rank order analyses to identify gender effects, when coding females $=0$ and males $=1$, significant correlations were observed, as follows: ASAA $(\mathrm{r}=-0.506, \mathrm{p}<0.001, \mathrm{n}=158), \mathrm{IL}-1 \beta(\mathrm{r}=-0.271, \mathrm{p}<0.001$, 
$\mathrm{n}=187)$, TNF- $\alpha(\mathrm{r}=-0.159, \mathrm{p}=0.032, \mathrm{n}=182)$, sTNF RI $(\mathrm{r}=0.625, \mathrm{p}<0.001, \mathrm{n}=179)$, and IL-2 $\mathrm{sR} \alpha(\mathrm{r}=-0.400$, $\mathrm{p}<0.001, \mathrm{n}=175$ ). The mainly negative (female-associated) correlations, except for sTNF RI (male-associated), reflect their gender-specific concentrations (table 1). The opposite correlations of sTNF RI versus IL- $2 \mathrm{sR} \alpha$ are reflected by a marked difference in their respective median concentration ratios, i.e. 1.97 in men and 0.89 in women (table 1). Analysis of cohort entry age revealed significant correlations, as follows: $\mathrm{CRP}(\mathrm{r}=0.275, \mathrm{p}<0.001, \mathrm{n}=225)$; ASAA $(\mathrm{r}=0.231, \mathrm{p}=0.004, \mathrm{n}=158)$; IL- $1 \beta(\mathrm{r}=-0.224$, $\mathrm{p}=0.002, \mathrm{n}=187)$, and TNF- $\alpha(\mathrm{r}=0.317, \mathrm{p}<0.001, \mathrm{n}=$ $182)$, revealing a negative age association only with IL-1 $\beta$.

Clinically Elevated CRP Concentrations $(8+m g / l)$

Differed in pre-RA versus CN Subjects

The log-transformed normalized CRP mean concentration of 46 pre-RA $(5.95 \pm 1.60 \mathrm{SE})$ did not quite differ $(\mathrm{p}=0.051)$ from the $179 \mathrm{CN}(2.70 \pm 0.29 \mathrm{SE})$ by t test with unequal variances assumed (table 2). However, the frequency of clinically elevated CRP $(8+\mathrm{mg} / \mathrm{l})$ levels was significantly $(\mathrm{p}=0.010)$ greater in the 46 pre-RA $(\mathrm{n}=8$, $17.4 \%)$ subjects than in the $179 \mathrm{CN}(\mathrm{n}=9,5.0 \%)$. The preRA status was associated with elevated CRP levels (OR $4.15,95 \%$ CI 1.48-11.62, $\mathrm{p}=0.007$ ), independently of gender and interval in years from cohort entry to RA onset, variables included in the MRA model. The pre-RA status remained an independent predictor of elevated CRP, when a 7-score gradient of smoking behaviors was also added to the model (data not shown). When a positive versus negative rheumatoid factor (RF) assay, as previously reported [25], was substituted in the model for smoking behaviors, pre-RA remained an independent predictor of elevated CRP $(\mathrm{p}=0.046)$, but not positive $\mathrm{RF}$ $(\mathrm{p}=0.107)$ (data not shown).

\section{Other Immunological Markers Did Not Differ}

between pre-RA and CN Subjects

Unlike CRP, neither the alternate APP (ASAA) nor the assayed cytokines, receptors, or the IL-1 $\beta$ receptor antagonist (IL-1ra) differed between the total pre-RA and $\mathrm{CN}$ subjects, or within each gender group (table 2). The 2 -fold ratio of sTNF-RI to IL-2sR $\alpha$ concentrations in males versus females was observed in each study group, suggesting a prominent gender dimorphism.

\section{Correlations of Immune Network Factors in Female pre- $R A$ versus $C N$ Subjects}

Serum CRP levels were associated with IL- 6 in pre-RA and in $\mathrm{CN}$ females (table 3), as may be expected [9-10].
Strong age-adjusted correlations also occurred between CRP and ASAA in both pre-RA and CN subjects (table 3). In the larger female $\mathrm{CN}$ sample, $\mathrm{CRP}$ was also associated significantly with IL-1ra, TNF- $\alpha$, and sTNF-RI. Similar strengths of correlations were noted in the pre-RA subjects but were not significant in that smaller sample. In the female controls, ASAA further correlated with sTNF$\mathrm{RI}$, but this association was not observed in the pre-RA sample.

The inflammatory cytokines, IL-1 $\beta$, IL- 6 , and TNF$\alpha$, correlated significantly among each other in the control subjects (table 3). In the pre-RA sample, none of the inflammatory cytokines correlated significantly, partly due to the smaller sample size. In both female subsets, IL1 ra correlated strongly with IL- 6 and with TNF- $\alpha$. The IL-1ra correlation was also strong with sTNF RI, but it was significant only in the larger female control sample (table 3). The correlation of IL-2sR $\alpha$ with sTNF RI was only significant in female controls, but its strength did not differ from that in pre-RA subjects. Overall, the immunomarker patterns displayed comparable strengths of respective correlations in the female study groups, and no difference was observed in strengths of correlations.

\section{Correlations of Immune Network Factors in Male pre-RA versus CN Subjects}

Strong age-adjusted correlations occurred between CRP and ASAA in both pre-RA and CN male subjects (table 4), as observed in females (table 3). In the larger male CN cohort, CRP further correlated with TNF- $\alpha$, sTNF-RI, and IL-2sR $\alpha$. The smaller sample of pre-RA subjects did not reveal such significant associations, although no difference in strength of correlations was observed. In males, a difference $(p=0.033)$ in the correlations of IL-1 $\beta$ with IL-1ra was noted between pre-RA ( $\mathrm{r}=$ $-0.637, \mathrm{p}=0.048, \mathrm{n}=11)$ and $\mathrm{CN}(\mathrm{r}=0.059, \mathrm{p}=0.681$, $\mathrm{n}=52$ ) subjects (table 4 ). No other difference in strength of correlations was observed between the male study groups. Again, IL-2sR $\alpha$ mainly correlated with the other receptor, sTNF-RI, in both study groups (table 4).

\section{Correlations of Age- and Gender-Adjusted Immune \\ Markers in Total pre-RA versus $C N$}

In total subjects, the pre-RA and $\mathrm{CN}$ immune network correlations were age and gender controlled (table 5). Again, CRP and ASAA were strongly correlated in both subject groups. The IL-6 levels (measured in females only) correlated with CRP in both groups, but not with ASAA. In each study group, IL-6 and sTNF-RI revealed the strongest correlations (table 5). Among the inflam- 
Table 3. Immune network correlations of female pre-RA (top) and control (bottom) cohort subjects using Spearman's age-adjusted values

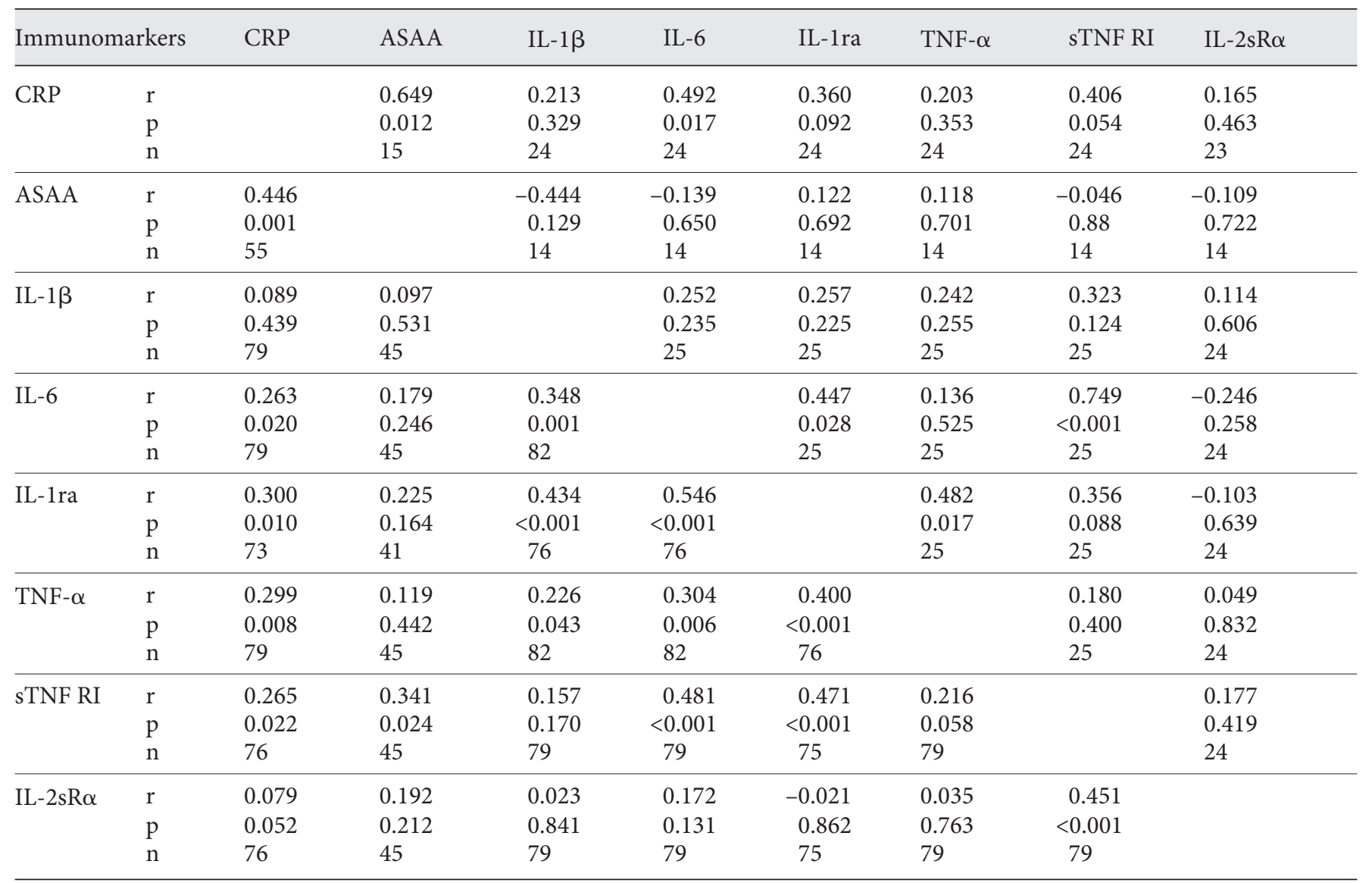

matory cytokines, IL- 6 correlated significantly with both IL-1 $\beta$ and TNF- $\alpha$ only in the larger control sample. In both study groups, IL-6 correlated strongly with IL-1ra (table 5). Three pairs of immune markers had opposite signs of correlations and showed significant $(\mathrm{p}<0.050)$ differences, being positive in $\mathrm{CN}$ and negative in the preRA: IL- $1 \beta$ with ASAA, IL- $1 \beta$ with IL-1ra, and ASAA with IL-2sR $\alpha$ (table 5). As in the separate genders, IL-2sR $\alpha$ correlated mainly with the other receptor, sTNF-RI, being significant in the control group (table 5). Overall, the bivariate correlations suggest similar magnitudes of immunomarker associations in the total pre-RA and $\mathrm{CN}$ study groups.

\section{Correlations in Total Female (Top) versus Male (Bottom) Subjects}

Females revealed stronger correlations of IL-1ra with both IL-1 $\beta(\mathrm{p}=0.019)$ and TNF- $\alpha(\mathrm{p}=0.004)$ compared to males (table 6). Except for the preceding IL-1 ra correla- tions with inflammatory cytokines, the strengths of associations did not differ significantly among the total gender groups and were similar overall.

\section{PCA of Total Subjects Using Normalized Values}

(table 7)

The PCA model of total subjects did not include ASAA or IL- 6 values, as ASAA assays were not performed in the first set females, and IL- 6 was not measured in males. In a PCA model of 158 subjects (95 females and 63 males), 5 components emerged from 9 factors, including 6 immune network biomarkers, entry age, gender, and the pre-RA versus $\mathrm{CN}$ variable (table 7). The 5 components included 1 or more factor loadings of 0.500 or greater, and explained $77.4 \%$ of the total variance. The 1st component may be labeled 'age at cohort entry', explaining $20.7 \%$ of the variance. Cohort entry age had the highest loading $(0.849)$ and was associated with high loadings by TNF- $\alpha$ (0.744) and CRP (0.541), 
Table 4. Immune network correlations of male pre-RA (top) and control (bottom) cohort subjects using Spearman's age-adjusted values

\begin{tabular}{|c|c|c|c|c|c|c|c|c|c|}
\hline \multicolumn{2}{|c|}{ Immunomarkers } & \multirow[t]{3}{*}{ CRP } & \multirow{2}{*}{$\begin{array}{c}\text { ASAA } \\
0.647\end{array}$} & \multirow{2}{*}{$\begin{array}{r}\text { IL-1 } \beta \\
-0.232\end{array}$} & \multirow[t]{3}{*}{ IL- $6^{b}$} & \multirow{2}{*}{$\begin{array}{c}\text { IL-1ra } \\
0.432\end{array}$} & \multirow{2}{*}{$\begin{array}{l}\text { TNF- } \alpha \\
0.246\end{array}$} & sTNF RI & IL- $2 s R \alpha$ \\
\hline CRP & $\mathrm{r}$ & & & & & & & 0.342 & -0.153 \\
\hline & $\mathrm{p}$ & & 0.007 & 0.405 & & 0.212 & 0.397 & 0.232 & 0.619 \\
\hline \multirow[t]{2}{*}{ ASAA } & $\mathrm{r}$ & 0.408 & & -0.432 & & 0.639 & -0.167 & 0.336 & 0.036 \\
\hline & $\mathrm{p}$ & 0.001 & & 0.108 & & 0.047 & 0.569 & 0.240 & 0.906 \\
\hline \multirow[t]{3}{*}{ IL-1 $\beta$} & $\mathrm{r}$ & 0.212 & 0.121 & & & $-0.637^{a}$ & 0.400 & -0.263 & 0.458 \\
\hline & $\mathrm{p}$ & 0.095 & 0.347 & & & 0.048 & 0.157 & 0.364 & 0.116 \\
\hline & $\mathrm{n}$ & 64 & 64 & & & 11 & 15 & 15 & 14 \\
\hline \multirow[t]{2}{*}{ IL-6 ${ }^{\mathrm{b}}$} & $\mathrm{r}$ & & & & & & & & \\
\hline & $\mathrm{p}$ & & & & & & & & \\
\hline \multirow[t]{3}{*}{ TNF- $\alpha$} & $\mathrm{r}$ & 0.335 & 0.001 & 0.000 & & -0.012 & & 0.391 & 0.480 \\
\hline & $\mathrm{p}$ & 0.009 & 0.997 & 0.998 & & 0.935 & & 0.167 & 0.097 \\
\hline & $\mathrm{n}$ & 60 & 60 & 60 & & 52 & & 15 & 14 \\
\hline \multirow[t]{3}{*}{ sTNF RI } & $\mathrm{r}$ & 0.313 & 0.229 & 0.171 & & 0.118 & 0.244 & & 0.479 \\
\hline & $\mathrm{p}$ & 0.016 & 0.081 & 0.195 & & 0.411 & 0.063 & & 0.098 \\
\hline & $\mathrm{n}$ & 60 & 60 & 60 & & 52 & 60 & & 14 \\
\hline \multirow[t]{3}{*}{ IL- $2 \mathrm{sR} \alpha$} & $\mathrm{r}$ & 0.275 & 0.282 & 0.252 & & 0.052 & 0.195 & 0.433 & \\
\hline & $\mathrm{p}$ & 0.039 & 0.034 & 0.089 & & 0.718 & 0.145 & 0.001 & \\
\hline & $\mathrm{n}$ & 58 & 58 & 58 & & 52 & 58 & 58 & \\
\hline
\end{tabular}

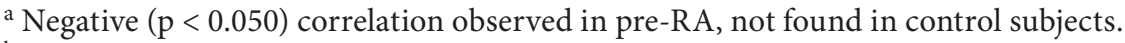

b Assayed only in females.

results which are consistent with preceding analyses (table 1). The 2nd component may be labeled 'gender', explaining $19.2 \%$ of the variance. This component had a high gender loading of 0.801 , and an even higher loading by sTNF-RI (0.935). The 3rd component may be labeled 'IL-1ra and IL-1 $\beta$ ', explaining $15.8 \%$ of the variance, having respective loadings of 0.793 and 0.743 . The 4 th component included only the 'pre-RA versus CN' variable, explaining $11.4 \%$ of the variance, with loading of 0.967 . The 5th component had heavy loading (0.991) only by IL-2sR $\alpha$, explaining $10.4 \%$ variance.

\section{A Tentative Integrative Model of Interrelations among} the Total Variables (fig. 2)

A working model of total variable interrelations was derived using MRA and assumptions from the PCA re- sults that gender and aging are independent effectors of the immunological variables. Also, inflammatory cytokines are assumed to effect the other biomarkers (fig. 2). The derived integrated relations are consistent with the preceding bivariate correlations (tables 3-6) and PCA, but offer a broader multivariate hypothetical schema for testing in further research.

\section{Discussion}

The greater frequency of clinically elevated CRP $(8+$ $\mathrm{mg} / \mathrm{dl}$ ) levels in pre-RA (17.4\%) compared to CN (5.0\%) was derived from the combined gender cohort $(\mathrm{n}=215)$. An earlier RAPS analysis in males alone [32] revealed that $4(22.1 \%)$ of 18 male pre-RA subjects versus 4 (5.6\%) of 72 
Table 5. Immune network correlations of total pre-RA (top) and control (bottom) cohort subjects using Spearman's age- and sex-adjusted values

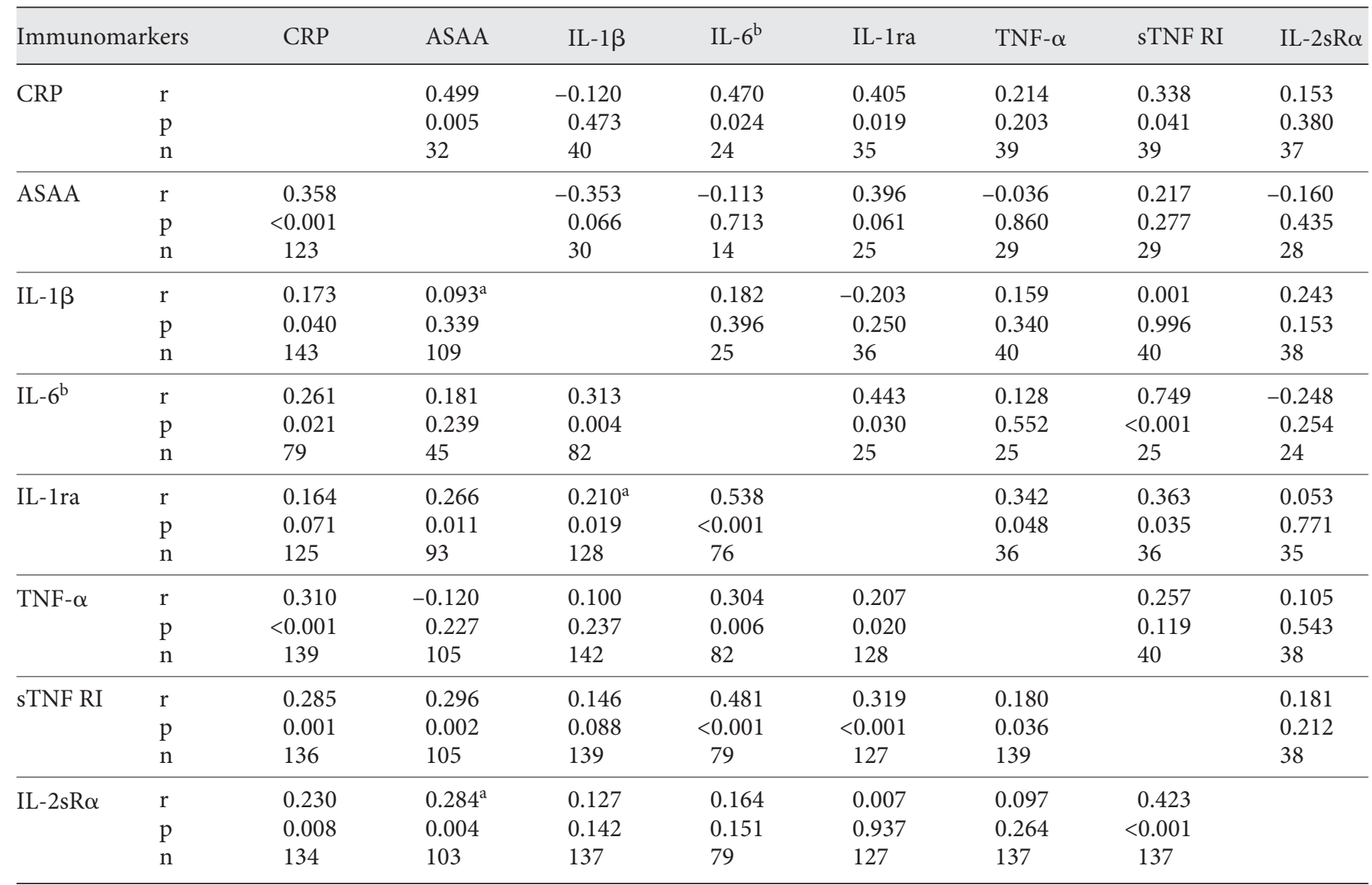

${ }^{\mathrm{a}}$ Positive correlations in control, but negative in pre-RA subjects, $\mathrm{p}<0.050 .{ }^{\mathrm{b}}$ Assayed only in females.

$\mathrm{CN}$ had such elevated CRP values $(\mathrm{p}=0.048)$. A positive $\mathrm{RF}$ was found in $6(33.3 \%)$ of the 18 pre-RA subjects and in $6(8.3 \%)$ of the $72 \mathrm{CN}(\mathrm{p}=0.012)$. Although our previous study [32] found concordance of elevated CRP and positive RF levels in males, i.e. 4 in pre-RA subjects and none in $\mathrm{CN}(\mathrm{p}=0.005)$, current multivariate analyses in total subjects revealed an independent association with pre-RA status.

A case-control cohort study of blood donors in the Netherlands [33] found slightly higher median CRP concentrations in multiple serum samples from 79 pre-RA subjects compared to 79 matched CN. Differences were significant during the shorter time periods between serum testing and the onset of symptoms: $0-1$ year $(\mathrm{p}=$ $0.001), 1-2$ years $(\mathrm{p}=0.035)$, and $4-5$ years $(\mathrm{p}=0.012)$, but not in longer 1 -year periods, extending to 15 years (me- dian 7.5 years). Sera from those pre-RA subjects who tested positive for either RF or anti-cyclic citrullinated peptide (anti-CCP) had slightly higher CRP concentrations than those with negative tests ( $\mathrm{p}$ value not provided). The above-mentioned higher serum CRP levels of pre-RA subjects were found with or without associated positive RF or anti-CCP results [33].

Besides the RAPS, pre-illness sera from populationbased healthy subjects who later developed RA onset are few [12, 33, 34], the earliest being a Finnish cohort [34]. That study of 124 pre-RA (85 females and 39 males) and 3 matched CN per pre-RA case found no difference in the OR of study subjects by quintiles of CRP levels, or in many strata of gender, baseline age, and interval from cohort entry to RA onset [34]. Furthermore, RF status was not associated with CRP [34]. Our results and the preced- 
Table 6. Immune network correlations of total female (top) and male (bottom) cohort subjects using Spearman's age-adjusted values

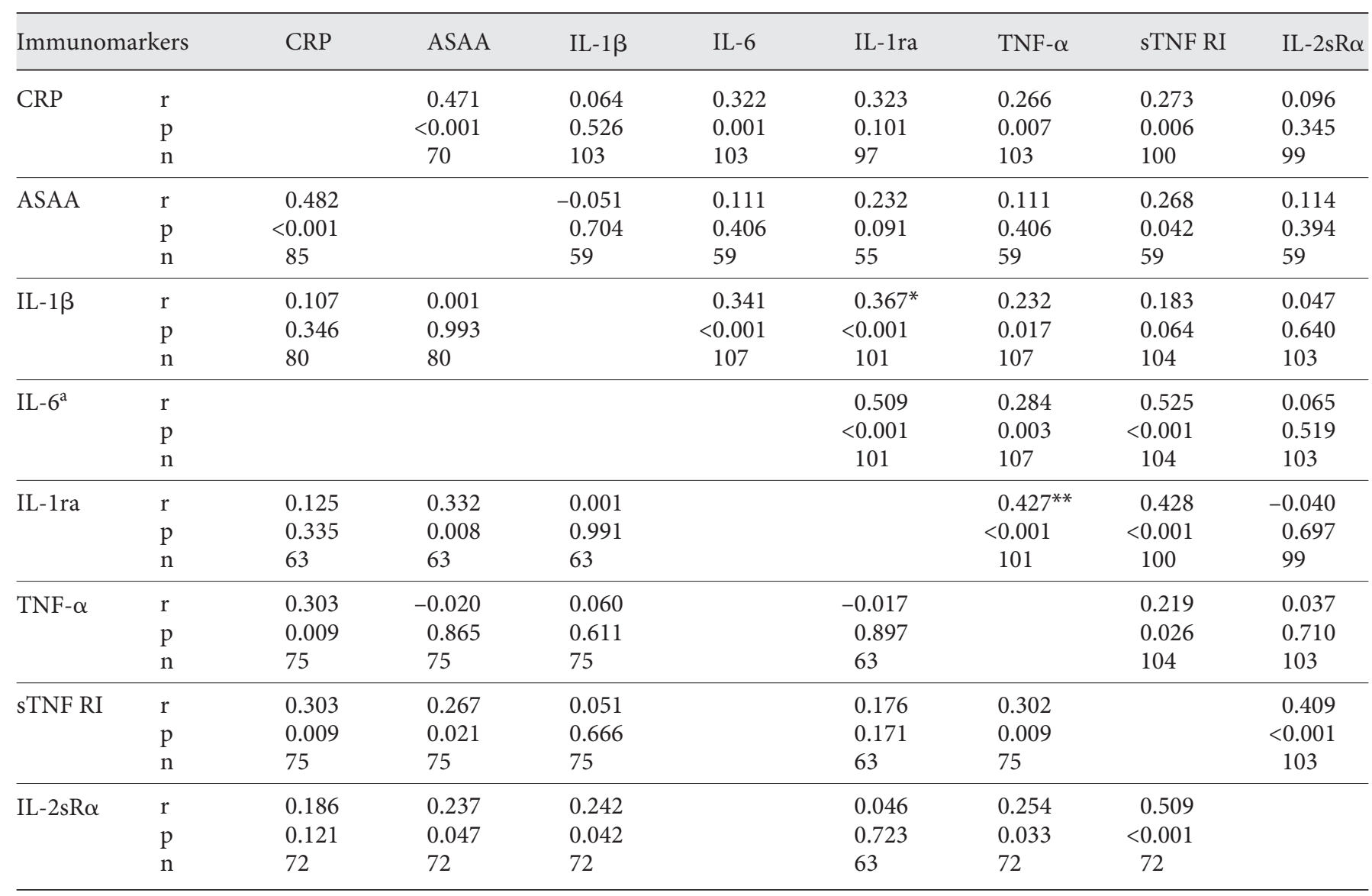

Positive and stronger correlations in total female compared to male subjects, ${ }^{*} \mathrm{p}<0.019 ;{ }^{* *} \mathrm{p}<0.004$.

a Assayed only in females.

ing CRP studies $[33,34]$ indicate the complexity of determining if elevated serum CRP levels may be associated with the risk of later developing clinical RA onset.

Our positive CRP findings relate to the percentile frequency of elevated levels, rather than to differences in medians [33] or quintile ranges [34]. In RAPS, elevated CRP was associated with pre-RA in males and in the first set of females, but no difference was found in the second set females. Additional cohort research is needed, particularly with longitudinal follow-up, to properly interpret a possible relation of serum CRP concentrations to risk of developing RA. If our CRP findings are supported, the slightly greater relative frequency of elevated levels (circa 10\%) in pre-RA versus CN may reflect a small minority of susceptibles who chronically exhibit increased inflammatory reactivity. Alternatively, a larger proportion of susceptibles may have amplified APP responsive- ness following intermittent stimulation from infectious agents or other triggers, detected only coincidentally at the times of baseline blood sampling.

Levels of the other APP, ASAA, inflammatory cytokines, receptors, and IL-1ra did not differ significantly between the total pre-RA subjects versus $\mathrm{CN}$ or by gender subgroups (table 2). Our findings are consistent with the preceding case-control study of a panel of cytokine-related markers among blood donors in Norway, which used the multiplex assay technique [12]. That study included 49 pre-RA ( 31 females and 18 males) and 245 matched CN (5 $\mathrm{CN}: 1$ pre-RA). Serum concentrations of the immune markers in the study groups were not provided. Rather, analyses were performed on the frequency of detectability and positivity levels. The latter was defined as the concentration cutoff values at the 95th percentile of control sera, when $5 \%$ or more had detectable levels [12]. Serum in- 
Table 7. Principal component analysis: factors and loadings of 158 Subjects*

\begin{tabular}{|c|c|c|c|}
\hline \multicolumn{2}{|l|}{ Component 1} & \multicolumn{2}{|l|}{ Component 2} \\
\hline factors & loadings & factors & loadings \\
\hline CLUE entry age & 0.849 & sTNF-R1 & 0.935 \\
\hline $\mathrm{TNF}-\alpha$ & 0.744 & gender $(f=0, m=1)$ & 0.801 \\
\hline CRP & 0.541 & & \\
\hline \multicolumn{2}{|l|}{ Component 3} & \multicolumn{2}{|l|}{ Component 4} \\
\hline factors & loadings & factors & loadings \\
\hline IL-1ra & 0.793 & pre-RA vs. CN & 0.967 \\
\hline \multirow[t]{4}{*}{ IL-1 $\beta$} & 0.743 & & \\
\hline & & \multicolumn{2}{|l|}{ Component 5} \\
\hline & & factors & loadings \\
\hline & & IL- $2 s R \alpha$ & 0.991 \\
\hline
\end{tabular}

* The 5 components explained $77.4 \%$ of the total variance: agerelated (20.7\%), Gender-related (19.2\%), IL-1ra and IL-1 $\beta$ (15.8\%), pre-RA vs. CN (11.4\%), and IL-2sR $\alpha$ (10.4\%).

flammatory cytokines were detected in only $10 \%$ or fewer of the study subjects and positivity was found in $6 \%$ or fewer subjects. Singleplex kits were used to measure IL-1ra and sTNF-RI, markers which were detected in $100 \%$ and almost one third of subjects, respectively. In the total sera, detectable and positive TNF- $\alpha$ levels were found in $3(6 \%)$ pre-RA subjects and in $6(2 \%) \mathrm{CN}(\mathrm{p}=0.176)$. The preceding 3 cases having had TNF- $\alpha$ positivity were among the 19 (16\%) pre-RA who had sera obtained within 5 years before RA diagnosis, which then exceeded expectations for that follow-up interval. The report concluded that cytokine positivity was not systematically different in premorbid cases compared to control sera [12].

The most recent comparative study of a cytokine profile primarily investigated first-degree relatives of North American Native (NAN) patients with RA [13]. Those relatives were considered to be RA susceptibles, though not classifiable as pre-RA, by EULAR definition [26]. Multiplex methods were used to assay serum cytokine levels of relatives, as compared to the RA patients and to NAN controls (table 2 in [13]). Multiple serum cytokine levels were significantly higher in first-degree relatives than in controls, particularly monocyte chemotactic protein 1 (MCP-1) as well as high-sensitivity CRP levels. No correlation was found between the latter immune markers

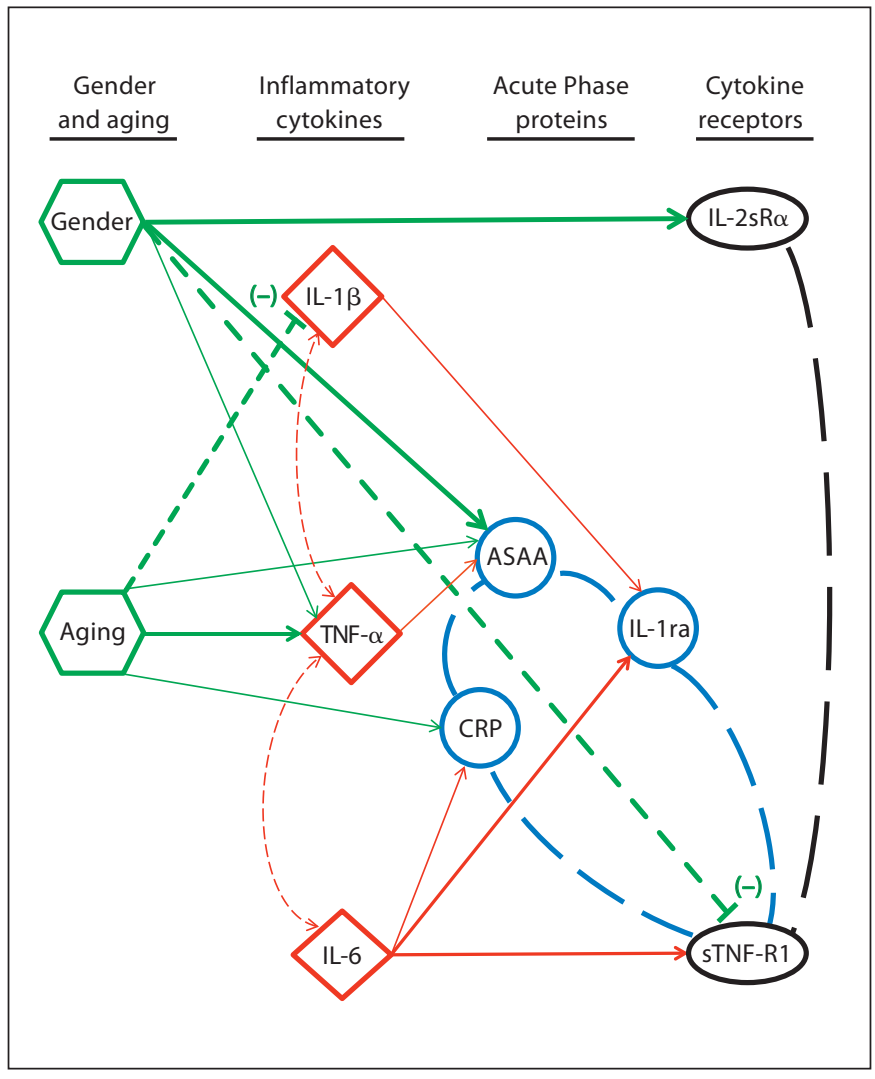

Fig. 2. A working integrative model of the complex interrelations of baseline serum inflammatory biomarkers observed in a crosssectional cohort, using the sequential MRA technique. Age and gender are assumed to be the highest level directional effectors of the other variables and the inflammatory cytokines to influence APP and receptor concentrations. For the inflammatory cytokine interrelations, age, but not gender, was entered in the models, since IL- 6 was assayed only in females. Except for the IL- 6 interrelations, other connecting lines were derived from values in total subjects, with the results being consistent in both genders. Straight lines were used for directional effectors and curved lines for intercorrelations among the reactor variables. The relative strengths of MRA-derived correlations are reflected in the line thicknesses: thinnest, $\mathrm{p}<0.050$; medium, $\mathrm{p}<0.010$, and thickest, $\mathrm{p}<0.001$. This integrated model of immune systems network interrelations needs further research testing.

within the first-degree relatives (Spearman's test $\mathrm{p}=$ 0.09). In that latter group, mean CRP levels (mg/l) did not differ by RF serological status between those 91 with positive tests (4.8) versus the 182 with negative (5.0) RF tests. Mean MCP-1 levels (pg/ml) did differ by RF status ( $\mathrm{p}=$ 0.020 ). Inflammatory cytokines were not indicated as independent variables in a logistic regression model discriminating first-degree relatives from NAN controls (table 3 in [13]). 
In our study, multiple significant age and gender correlations were found in the APP and cytokine-related factors (table 1; fig. 2). The observed bivariate correlations of serum concentrations in pre-RA and $\mathrm{CN}$ (tables 3-6) are not confounded by such demographic factors. The study groups were closely matched on these host variables and the correlations were also controlled. Assays were concurrently performed in matched sets of 1 pre-RA and $4 \mathrm{CN}$, whether tested in females, males, or total subjects. However, differences in serum concentrations between genders may be technically qualified. Their assays were performed in different periods (table 1; fig. 1), although repeatability analyses did not differ significantly between genders (table 1). Spearman's pairwise correlational analyses were adjusted for age within each specific gender as well as for both age and gender when comparing total pre-RA versus CN. Accordingly, the multiple significant bivariate correlations observed in the immune network profiles of the comparative study groups are not believed to be spuriously confounded by the demographic variables. The hypothetical model of total variable interrelations (fig. 2) attempts to derive a broader and more independent association of the host and immunologic factors. If such interrelational patterns can be confirmed, improved discrimination may be expected between study groups rather than simple observation of differences in concentration levels or in their bivariate correlations.

The validity of the results in this study depends upon the accuracy and precision of the ELISA techniques used to measure each independent analyte. The repeatability analyses in this study used intra-set percentile coefficients of variation $(\mathrm{CV})$ of reported results in paired tests [35]. Those CV (\%) were consistent with manufacturer's standards and comparable among the analytes and between subject samples (table 1). The ELISA method is stated to be the gold standard of individual cytokine measurements because of its greater precision and sensitivity compared to multiplex cytokine analysis methods $[20,21]$. To our knowledge, quantified correlations of such a panel of serum immune network factors have not been reported. Further investigations of this type may uncover major biological determinants of the interactions.

Overall, the strongest interrelation occurred between CRP and ASAA levels, as expected, and between sTNFRI and IL-2sR $\alpha$, which is not well recognized. Perhaps, the T-cell-related IL-2sR $\alpha$ (CD25) [36] may be controlled differently from the alternate receptor and the APPs. Serum IL- 6 was analyzed only in females and correlated strongly with CRP, consistent with the general consensus and earlier reports $[9,10]$, and more so than with ASAA levels. sTNF-RI levels were strongly associated with IL-6 and IL-1ra in females and with CRP generally. These host-specific correlational results had not previously been reported and need to be confirmed for more definitive interpretations.

The PCA results (table 7) on 158 combined subjects (95 females and 63 males) supported the correlational analyses and matrix tables (tables 3-6). Cohort entry age emerged in the 1st component, associated with CRP and TNF- $\alpha$. Gender emerged in the 2nd component, associated with strong sTNF RI loading. The PCA revealed strong loadings of IL-1 $\beta$ with IL-1ra in the 3rd component. Such a paired result is consistent with IL-1 $\beta$ being the main inducer of IL-1ra [37]. The pre-RA versus CN variable emerged exclusively as the 4th component and showed heavy loading (0.983). Serum IL-2sR $\alpha$ loaded heavily in the 5 th component as the exclusive factor. This PCA result reflects its weak associations with other immunomarkers, except for sTNF-RI, which loaded heavily with gender in the 2nd component.

Additional PCAs were performed on variously stratified subject groups, revealing slightly different patterns of component loadings (subject of a separate report). For example, in 95 females, IL-1 $\beta$ and IL-1ra emerged as paired factors in the 1st of 4 components. On the contrary, in 63 males, IL-1 $\beta$ was the sole factor in the 4 th of 4 components. In 124 control subjects, TNF- $\alpha$ had the strongest loading (0.775) in the 1st of 3 components, whereas in 34 pre-RA subjects it loaded strongest (0.767) in the 3 rd of 3 components. Such PCA data may indicate subtle subject group differences in correlational patterns, which deserve further investigation. Overall, the pre-RA versus $\mathrm{CN}$ status did not reveal significant effects upon the immunological variables, permitting their combined analyses in MRA, to derive the tentative integrative model (fig. 2).

The results of this study need to be qualified technically, since all assays were not performed concurrently. However, measurements were always performed blindly on serum sets of 1 pre-RA and 4 matched CN. Individual measurements by ELISA are reported to have greater accuracy and precision than the multiplex techniques [20, 21]. However, results may be further improved by testing all factors concurrently in a single immunology laboratory dedicated to research on the inflammatory network systems. Future research may reveal findings not detected in this study. 


\section{Acknowledgements}

The CLUE study, Campaign Against Cancer and Stroke, was funded in 1974 by grant CA 11849 from the National Cancer Institute. We thank Becky Hawkins, Laura Farney, and Gyuzide Redzhebova for their valuable technical assistance in completing this manuscript, and Marie McWhirter for helping to compose the figures. Support for this project was provided by the Department of Medicine, University of Illinois College of Medicine at Peoria, and by a gift from the MTM Foundation.

\section{Disclosure Statement}

The authors report no potential conflict of interest.

\section{References}

1 Akira S, Hirano T, Taga T, Kishimoto T: Biology of multifunctional cytokines: IL 6 and related molecules (IL 1 and TNF). FASEB J 1990;4:2860-2867.

-2 Gabay C, Cakir N, Moral F, Roux-Lombard P, Meyer O, Dayer JM, et al: Circulating levels of tumor necrosis factor soluble receptors in systemic lupus erythematosus are significantly higher than in other rheumatic diseases and correlated with disease activity. J Rheumatol 1997;24:303-308.

3 Kushner I: Regulation of the acute phase response by cytokines. Perspect Biol Med 1993; 36:611-622.

-4 Abeywardena MY, Leifert WR, Warnes KE, Varghese JN, Head RJ: Cardiovascular biology of interleukin-6. Curr Pharm Des 2009; 15:1809-1821.

5 Ganapathi MK, Schultz D, Mackiewicz A, Samols D, Hu SI, Brabenec A, Macintyre SS, Kushner I: Heterogeneous nature of the acute phase response: differential regulation of human serum amyloid A, C-reactive protein, and other acute phase proteins by cytokines in Hep 3B cells. J Immunol 1988;141: 564-569.

6 Badolato R, Oppenheim JJ: Role of cytokines, acute-phase proteins, and chemokines in the progression of rheumatoid arthritis. Semin Arthritis Rheum 1996;26:526-538.

7 Yao C, Wei W, Li X, Hosoi K: Acute phase protein induction by experimental inflammation in the salivary gland. J Oral Pathol Med 2005;34:364-367.

8 Jiang S, Xia D, Samols D: Expression of rabbit C-reactive protein in transgenic mice inhibits development of antigen-induced arthritis. Scand J Rheumatol 2006;35:351-355.

$\checkmark 9$ Hager K, Machein U, Krieger S, Platt D, Seefried G, Bauer J: Interleukin- 6 and selected plasma proteins in healthy persons of different ages. Neurobiol Aging 1994;15: 771-772.

10 Taaffe DR, Harris TB, Ferrucci L, Rowe J, Seeman TE: Cross-sectional and prospective relationships of interleukin- 6 and C-reactive protein with physical performance in elderly persons: MacArthur studies of successful aging. J Gerontol A Biol Sci Med Sci 2000; 55:M709-M715.
11 Masi AT, Aldag JC, Sipe JD, Malamet RL: Women before clinical onset of RA (preRA) had strong correlations of baseline serum IL-6 with VEGF and IL-1 beta with acute serum amyloid A (ASAA) plus soluble TNFreceptor type I (sTNF-RI), not observed in cohort controls (CN). Arthritis Rheum 2006;54:S203.

12 Jorgensen KT, Wiik A, Pedersen M, Hedegaard CJ, Vestergaard BF, Gislefoss RE, Kvien TK, Wohlfahrt J, Bendtzen K, Frisch M: Cytokines, autoantibodies and viral antibodies in premorbid and postdiagnostic sera from patients with rheumatoid arthritis: case-control study nested in a cohort of Norwegian blood donors. Ann Rheum Dis 2008; 67:860-866.

13 El-Gabalawy HS, Robinson DB, Smolik I, Hart D, Elias B, Wong K, Peschken CA, Hitchon CA, Li X, Bernstein CN, Newkirk MM, Fritzler MJ: Familial clustering of the serum cytokine profile in the relatives of rheumatoid arthritis patients. Arthritis Rheum 2012;64:1720-1729.

14 Lannergård A, Larsson A, Kragsbjerg P, Friman G: Correlations between serum amyloid A protein and C-reactive protein in infectious diseases. Scand J Clin Lab Invest 2003; 63:267-272.

15 Manicourt DH, Triki R, Fukuda K, Devogelaer JP, Nagant de Deuxchaisnes C, Thonar EJ: Levels of circulating tumor necrosis factor alpha and interleukin- 6 in patients with rheumatoid arthritis: relationship to serum levels of hyaluronan and antigenic keratin sulfate. Arthritis Rheum 1993;36:490-499.

16 van Leeuwen MA, Westra J, Limburg PC, van Riel PL, van Rijswijk MH: Clinical significance of interleukin- 6 measurement in early rheumatoid arthritis: relation with laboratory and clinical variables and radiological progression in a three year prospective study. Ann Rheum Dis 1995;54:674677.

17 Cunnane G, Grehan S, Geoghegan S, McCormack C, Shields D, Whitehead AS, Bresnihan B, Fitzgerald O: Serum amyloid A in the assessment of early inflammatory arthritis. J Rheumatol 2000;27:58-63.
18 Lash GE, Scaife PJ, Innes BA, Otun HA, Robson SC, Searle RF, Bulmer JN: Comparison of three multiplex cytokine analysis systems: Luminex, SearchLight and FAST Quant. J Immunol Methods 2006;309:205-218.

19 duPont NC, Wang K, Wadhwa PD, Culhane JF, Nelson EL: Validation and comparison of luminex multiplex cytokine analysis kits with ELISA: determinations of a panel of nine cytokines in clinical sample culture supernatants. J Reprod Immunol 2005;66:175191.

20 Richens JL, Urbanowicz RA, Metcalf R, Corne J, O'Shea P, Fairclough L: Quantitative validation and comparison of multiplex cytokine kits. J Biomol Screen 2010;15:562568.

21 Churchman SM, Geiler J, Parmar R, Horner EA, Church LD, Emery P, et al: Multiplexing immunoassays for cytokine detection in the serum of patients with rheumatoid arthritis: lack of sensitivity and interference by rheumatoid factor. Clin Exper Rheumatol 2012; 30:534-542.

22 Helzlsouer KJ, Alberg AJ, Gordon GB, Longcope C, Bush TL, Hoffman SC, Cornstock GW: Serum gonadotropins and steroid hormones and the development of ovarian cancer. JAMA 1995;274:1926-1930.

23 Rothman N, Cantor KP, Blair A, Bush D, Brock JW, Helzlsouer K, Zahm SH, Needham LL, Pearson GR, Hoover RN, Cornstock GW, Strickland PT: A nested case-control study of non-Hodgkin lymphoma and serum organochlorine residues. Lancet 1997;350: 240-244.

24 Alberg AJ, Gordon GB, Hoffman SC, Comstock GW, Helzlsouer KJ: Serum dehydroepiandrosterone and dehydroepiandrosterone sulfate and the subsequent risk of developing colon cancer. Cancer Epidemiol Biomarkers Prev 2000;9:517-521.

25 Masi AT, Aldag JC: Integrated neuroendocrine immune risk factors in relation to rheumatoid arthritis: should rheumatologists now adopt a model of a multiyear, presymptomatic phase? Scand J Rheumatol 2005;34:342-352. 
26 Gerlag DM, Raza K, van Baarsen LG, Brouwer E, Buckley CD, et al: EULAR recommendations for terminology and research in individuals at risk of rheumatoid arthritis: report from the Study Group for Risk Factors for Rheumatoid Arthritis. Ann Rheum Dis 2012;71:638-641.

27 Arnett FC, Edworthy SM, Bloch DA, McShane DJ, Fries JF, et al: The American Rheumatism Association 1987 revised criteria for the classification of rheumatoid arthritis. Arthritis Rheum 1988;31:315-324.

$\checkmark 28$ Masi AT, Feigenbaum SL, Chatterton RT: Hormonal and pregnancy relationships to rheumatoid arthritis: convergent effects with immunologic and microvascular systems. Semin Arthritis Rheum 1995;25:127.

29 Masi AT: Incidence of rheumatoid arthritis: do the observed age-sex interaction patterns support a role of androgenic-anabolic steroid deficiency in its pathogenesis? Br J Rheumatol 1994;33:697-699.
30 Shields MJ, Siegel JN, Clark CR, Hines KK, Potempa LA, Gewurz H, Anderson B: An appraisal of polystyrene-(ELISA) and nitrocellulose-based (ELIFA) enzyme immunoassay systems using monoclonal antibodies reactive toward antigenically distinct forms of human C-reactive protein. J Immunol Methods 1991;141:253-261.

31 Dixon WJ, Tukey JW: Approximate behavior of the distribution of Winsorized $t$ (Trimming/Winsorization 2). Technometrics 1968; 10:83-98.

32 Masi AT, Aldag JC, Sipes J: Do elevated levels of serum C-reactive protein predict rheumatoid arthritis in men: correlations with preRA status and baseline positive rheumatoid factors. J Rheumatol 2001;28:2359-2361.

-33 Nielen MM, van Schaardenburg D, Reesink HW, Twisk JW, van de Stadt RJ, et al: Increased levels of C-reactive protein in serum from blood donors before the onset of rheumatoid arthritis. Arthritis Rheum 2004;50: 2423-2427.
4 Aho K, Palosuo T, Knekt P, Alha P, Aromaa A, Heliovaara M: Serum C-reactive protein does not predict rheumatoid arthritis. J Rheumatol 2000;27:1136-1138.

35 Szklo M, Nieto FJ: Quality assurance and control; in: Epidemiology: Beyond the Basics. Gaithersburg, Aspen, 2000, pp 398-399.

36 Praditpornsilpa K, Avihingsanon Y, Kupatawintu P, Songpanich S, Pisitkul T, Kansanabuch T, Eiam-Ong S, Chusil S, O-Charoen R, Tungsanga K: Monitoring of T-cell subsets in patients treated with anti-CD 25 antibody. Transplant Proc 2004;36:487S491S.

37 Gabay C, Porter B, Guenette D, Billir B, Arend WP: Interleukin-4 (IL-4) and IL-13 enhance the effect of IL- $1 \beta$ on production of IL-1 receptor antagonist by human primary hepatocytes and hepatoma HepG2 cells: differential effect on C-reactive protein production. Blood 1999;93:1299-1307. 